\title{
The Application of TBLT to Oral English Teaching in Junior High School in China
}

\author{
Huang Ling \\ School of Foreign Language, Leshan Normal University, Leshan, Sichuan, China
}

\begin{abstract}
The task-based Language teaching is the teaching theory put forward by foreign language teaching method researchers on the basis of the large quantity of studies and practice in the 1980s. It advocates learning from "doingit" and the interactive learning styles: learning from experiencing, practicing, participating, communicating and cooperating. The national New Standard for English Curriculum advocates the implementing of TBLT in Junior High School in China. At present, many scholars have investigated the application in terms of teaching of reading, writing and so on, but only a few have involved the study about the application of TBLT in oral English teaching. Through the analysis of the present situation of oral English teaching in Junior High School in China, this thesis aims to solve the teaching problems by applying TBLT to oral English teaching on the basis of the previous study.
\end{abstract}

Keywords: Task-based language teaching; Oral English; Junior high school in China.

(c) () CC BY: Creative Commons Attribution License 4.0

\section{Introduction}

With the globalization of economy and the further reinforcement of the international communication, English, especially Oral English is dramatically demanded on many occasions. The modern society needs more and more people skilled in oral English, but the average level of oral English among Chinese students in junior high school is very low. Therefore, it is very essential to cultivate students' ability to use English for communication. Task-based Language Teaching as an important approach to improve students' learning ability efficiency and to foster students' communicative competence is praised by teachers in general.

Task-based Language Teaching is, in fact, a further development of Communicative Language Teaching. It is considered as one of the most effective language teaching methods in 1980s. It emphasizes "learning by doing" and provides students an opportunity to improve their speaking skills through authentic, functional activities.

Task-based Language Teaching has attracted worldwide attention since it appeared in1980s. Many linguistic experts such as David Nunan and Jane Willis did a great many studies and explorations on TBLT. In 1989, Nunan punished Designing Tasks for the Communicative Classroom, a milestone of Task-based Approach to language teaching. And in 1996, Jane Willis published a monograph A Framework for Task-based learning, a book very useful for task-based teaching. In China, Task-based Language Teaching first began in Hong Kong. In 2001, the National New Standard for English Curriculum also advocates Task-based Approach in English teaching.

In recent years, Task-based Language Teaching has widely promoted in English language teaching. However, most researchers pay more attention to the adoption of TBLT in reading or writing, and fewer focus on the adoption of the TBLT in Oral English teaching. Therefore, this thesis mainly discusses the present situation of oral English teaching in Junior High School, the application of Task-based Language Teaching in Oral English class and the inspiration from the application of TBLT in China.

\section{Literature Review}

TBLT was first developed in India in the 1980s. Many language researchers and linguists have done lots of conceptual and empirical researches on it. In this part, the author mainly reviews the definition of task and TBLT, the development of TBLT at home and abroad.

\subsection{The Definition of Task and TBLT}

As for the definition of task, different experts hold different views.

Nunan (1989) explains the task from communication perspective in which task is a piece of classroom work which involves learners in comprehending, manipulating, producing or interacting in the target language while their attention is principally focused on meaning rather than form.

Willis (1996), considers tasks as activities where the target language is used by the learner for a communicative purpose in order to achieve an outcome.

From the above definitions we can see that they share two points in common. One point is that they all emphasize the fact that pedagogical tasks involve in communicative language use in which the user's attention is focused on meaning rather than on form. The other point is that they emphasize outcome achieved through the tasks and the assessment of task is in terms of outcome. Effective communication is just what Oral English tries to achieve. 
Then for the definition of TBLT, Skehan defines task-based language teaching and learning as follows: "Instruction in which learners are given tasks to complete in the classroom makes the assumption that transacting tasks in this way will engage naturalistic acquisition mechanisms, cause the underlying inter language system to be stretched, and drive development forward."(1998:55).

Nunan (1999), defines task-based language teaching as an approach to design of language course in which the point of departure is not an ordered list of linguistic items, but a collection of task.

Task-based language teaching aims at making language classroom approximate to the target language environment. Students understand how native speakers use language to communicate through completing tasks instead of learning from books. It provides students with opportunities to use the language in their daily life.

\subsection{The Development of TBLT Worldwide}

TBLT has attracted much interest since it was first advocated by Prabhu in the 1980s. Prabhu did an experiment called Bangalore Project aiming at developing a methodology in a "substantial teaching" environment. His experiment was the first trial of TBLT which gained much attention from scholars around the world. Among them includes the famous linguists David Nunan, Jane Willis and so on.

Nunan (1989) put forward an integrated framework for communicative task made up of goals, input, activities, the teacher's role, the students' role and settings in his book Designing Tasks for Communicative Classroom. This book became the representative work of TBLT and helped teachers select, adapt or create their own communicative tasks. Then, Willis and Skehan developed TBLT. Willis (1996), proposed the procedure for TBLT, namely pre-task phase, task cycle phase and language focus phase in his book A Framework for Task-based Learning. Skehan reviews the development in cognitive psychology which proposes the goals of accuracy, complexity and fluency as the most relevant thing for TBLT.

Task-based Language Teaching, as an effective approach of foreign language teaching, has become international mainstream of English teaching. It has been adopted in America, Canada, Singapore and many other countries.

In China, the study of TBLT is still in the initial stage. Task-based Language Teaching first began in Hong Kong. In 1996, it was adopted in Hong Kong's teaching syllabus. According to the real situation of English teaching in China, many linguistics and teachers have done some researches and studies about TBLT. Gong and Luo (2003), hold that the task-based spoken English teaching is to divide the activities which people do in the social lives into several very specific tasks, and take training students to accomplish these tasks as teaching purpose. Wu Xuesong once did a research and stated that task-based instruction with relevant contexts or themes enables teachers to provide meaningful teaching and learning activities that engage learners in purposeful communication.

In 2001, Ministry of Education (2001) promulgated the New National Criterion for English Course which takes a favorable attitude towards TBLT and advocates experiencing, practicing, participating, communicating and cooperating, so students can obtain a sense of success.

\section{Current Situation of Oral English Teaching and Learning in Junior High School in China}

The nature of language is a communicative tool, whose main use is to build up and maintain social relations between people (Widdowson, 1996). Therefore, in order to master a language, we should master the four basic skills: listening, speaking, reading and writing, among which speaking is the most important skill. However, many Junior High School students in China are unqualified in oral English under the instruction of the Chinese traditional language approach. The author here will discuss the reasons from two aspects: on the part of students, on the part of teachers as well. And then the author will put emphasis on the importance to improve students' oral English.

\subsection{Factors of the Students}

\subsubsection{Lack of Motivation}

One of the reasons that Chinese students are unqualified in oral English is that they lack motivation of speaking English.

For a foreign language learner, motivation plays an undoubtedly important role. It is one of the most essential factors influencing students' success and failure in learning language. And it is also an important factor that influences students' speaking ability. Usually, there are two groups of motivation: intrinsic motivation and extrinsic motivation. As for learning oral English, some students learn it because they like it or they are interested in western culture. These are called intrinsic motivation. While others learn it because extrinsic factors, such as getting high scores or going abroad. These are called extrinsic motivation. As it is known to all, in a traditional teacher-centered classroom, teachers dominate the whole class and students have slim chance to speak English. The teachers seldom give the students tasks, and they just speak English themselves in class while the students are just listeners. The learning atmosphere is boring, so the students lose their interest in speaking English.

\subsubsection{Lack of Confidence}

Another reason is that students lack confidence in speaking English.

Students lack of confidence in class because of the traditional teaching methods which lay too much emphasis on linguistic knowledge and grammar. Meanwhile, the teachers seldom design appropriate tasks for the students. Sometimes, the tasks are too difficult for the students to complete. When students practice oral English, they are afraid of making mistakes. So they don't have confidence to open their mouth to speak. They feel nervous when they 
are about to speak English. This phenomenon is very common in China. A junior high school student said that: "Once I tried to speak English with my friends and after hearing the sentence from me like: 'what are you do this Sunday?' My friends always laughed at me: 'You cannot speak a sentence like this. You are so poor in English.' I felt so embarrassed that I dared not speak English in public from then on." It is inevitable that learners make mistakes during the process of studying. One can't master a language without making mistakes. So if a student is not afraid of making mistakes, he or she will have confidence in speaking English.

\subsection{Factors of the Teachers}

\subsubsection{Poor Teaching Methods}

Some English teachers in China don't have proper teaching methods.

As we all know that most teachers still adopt the traditional teacher-based approach. Teacher is a giver and students passive receiver. The teachers spend lots of time explaining the sentence structure, words, phrases and grammar rules mechanically and the students just take notes down and bear them in mind. Therefore, the classroom tends to be teacher-centered. The teacher controls the teaching procedure from the beginning to the end, while students have few opportunities to express their own ideas. This teaching method makes oral English class boring and students lose the interest in oral English. In this way, it is impossible for students to develop their communicative ability.

\subsubsection{Lack of Professional Skills}

Some English teachers don't have overall knowledge of English.

It is known to all that teachers play an important role in students' language acquisition. The improvement of the quality of English education depends on high-qualified English teachers. Therefore, in order to improve the quality of English teaching, we must strengthen the building of the team of English teachers. But in China, especially in some remote rural areas, teachers themselves don't have fluent oral English. If the teacher's pronunciation is not standard, he or she will mislead students. Besides, some teachers are lack of the knowledge of western cultures, so they teach students little about the cultures of English speaking countries which is very bad for the students, because culture is an indispensable part of a language. One can't learn a foreign language well without having any knowledge about its culture.

\subsection{The Importance of Improving Junior High School Students' Oral English in China}

As the economic globalization develops further and deeper, the worldwide communication is becoming increasingly frequent. English, as a modern communication tool, has gained more and more importance. Nowadays, it is believed by many people that the ultimate goal of learning a foreign language is to communicate, and communicative competence is mainly embodied as oral English. Oral English plays an important part in everyday interaction and most often the first impression of a person is based on his or her ability to speak fluently and comprehensibly. In real life, when judging one's language competence, it is often the speaking ability which would be referred. Thus, it is of great importance for junior high school students to improve their speaking ability.

Nowadays, TBLT as an effective method is praised by teachers in general. It demonstrates a lot of advantages for enhancing language learning. On one hand, it can attract students' interest and motivation. TBLT is a studentcentered class teaching and it provides various activities such as discussion, presentation and role-play for students to practice oral English. Therefore, students will be interested in speaking English and their motivation can be evoked. On the other hand, TBLT can enhance students' confidence. It emphasizes the meaningful communication and provides a circumstance for students to build up their confidence. In TBLT, teacher's roles are multiple. They are mainly task-designers, hierophants, monitors or assess mentors. In the course of accomplishing the assigned tasks by the teacher, students will first know what they are talking with each other, their first consideration is what to say and say it directly without caring too much about the grammar. In this way, students are encouraged to express their ideas freely in English and their confidence will be enhanced. Therefore, it is important to apply TBLT to oral English teaching in Junior High School.

\section{The Application of TBLT to Oral English Teaching in Junior High School in China}

In recent years, Task-Based Language Teaching gradually comes into our sights and lights the hope in English teaching. This relatively new teaching approach emphasizes "learning by doing" and provides a circumstance for students to build up their confidence and evokes their motivation. Students can enhance their oral English in the authentic, free, and harmonious environments. It is believed to be an effective way to improve students'speaking ability.

Therefore, this part mainly concerns how to apply TBLT to oral English teaching in Junior High School in China. The author will list the task-implementing model in oral English class and give examples to make an analysis of its practical importance. 


\subsection{Willis' Task-Implementing Model in Oral English Teaching}

In a task-based instruction classroom, the students begin to learn lesson with the task. When they have finished it, the teacher draws attention to the language points, making corrections and adjustments to the students' performances. To start with, Willis' task-implementing model will be introduced.

Once a task has been selected, the task can be executed in a number of ways. Accordingly, Willis (1996) presents a model which is designed to meet these different kinds of needs (see Table 1).

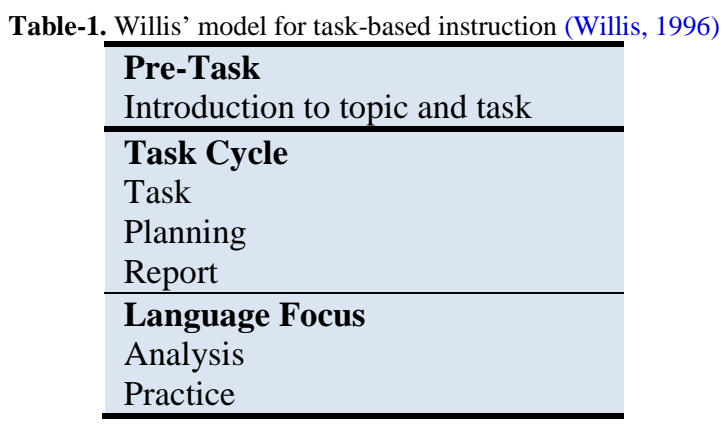

From Table 1, we can see that this model divides instruction into three stages: Pre-task, task cycle and language focus (Willis, 1996). These components have been carefully designed to create four optimum conditions for language acquisition and also provide rich opportunities to meet the needs of different learners.

\subsubsection{Pre-Task}

Willis (1996), holds that: "the pre-task phase will usually be the shortest stage in the framework. It could vary between two and twenty minutes, depending on the learners' degree of familiarity with the topic and the type of the tasks".

Pre-Task is very important to attract students' interest and improve their motivation. The teacher should introduce students a topic which is interesting and creative, and give students some key words or phrases which are related to the given topic. Then, the teacher can add some guiding activities to help students have a better understanding of the task and make them ready for the preparation. During this session, the teacher can also show students some pictures or share them some experiences to inspire their thoughts or write down some phrases on the blackboard to encourage them to speak out anything they can recall from their mind. At the same time, the teacher should also tell students the goal of the task and what they should do. For Junior High School students, some tasks may be easy for them to talk about, like topics about sports, music, family, school and so on. However, some tasks may be a little bit difficult for them, such as the narrow topic about "spaceship". The students may feel hard to say a lot about it. At this time, the teacher should lead them to call out their memories by giving them some related words they have already known. This stage aims at making the students activate the related old knowledge and have interest in the new ones at the same time.

\subsubsection{Task-Cycle}

Task-Cycle, the stage of consolidating new knowledge, is a good opportunity for students to open their mouth to speak. In this stage, the students are required to put all the language knowledge they have learned into use through finishing all the communication tasks. And Task-Cycle, the second phase in the task-based approach has three components_-task designing, planning and report (Willis, 1996).

\subsubsection{Task}

Students usually complete the task in pairs or groups, and then the teacher guides and encourages them to try various way of communication. Teachers all have the experience that the students' confidence grows when they realize they can do something without teachers' direct support. The task stage is a good opportunity for students to open their mouths to speak, work in pairs or groups to achieve the goals of the task.

According to Willis, the teacher's role as a monitor should be emphasized during this stage. It is no doubt that achieving a successful outcome of oral English teaching in Junior High School would not be guaranteed without the devotion of the teacher. In the traditional Oral English class, the teacher is always the center of the class and controls the students' activities. However, in TBLT class, the teacher is no longer the center; he or she is expected to act as a facilitator, a monitor, motivator or an evaluator. Besides, the roles of the students should also not be ignored. Students are much more active in the task-based oral English classroom. They are not passive recipients but excellent performers.

As for the task designing, it is the hardest thing to do in an oral English class. According to the principles of task selection, there are five oral task types. Tasks can be implemented by such activities as role-play, information gap, problem-solving, discussion and jigsaw. 


\subsubsection{Planning}

The planning stage comes after the task and before the report, forming the central part of the task cycle. It is mainly concerned with how to help the students plan their report effectively and maximize their learning opportunities (Willis, 1996).

Each group prepares oral or written forms to report to the whole class about their fulfillment of the task. The reporter should try their best to make the expression accurate and appropriate. At this time, the teacher should give students appropriate guidance and suggestions which mainly concern about how to plan their report more effectively. The teacher should also conduct a feedback session to discuss the success of the task and consider some suggestions for improving it. Students may discuss some issues, such as working together, performing in a group, amount of language input, things they enjoyed doing, things they didn't enjoy and so on. Assessment of the task will provide useful information for teachers when they plan further tasks.

\subsubsection{Report}

After finishing the task, each group can exchange the reports with each other to compare the results. At this moment, the teacher acts as an evaluator, assesses the fulfillment of each group.

When evaluating the students' fulfillment, the teacher should pay attention to the three main factors: time, form and support. The first one is time pressure. The time the teacher gives to the students should change according to the difficulty of the task. If the task is a little bit difficult, the teacher should provide students with plenty of time to prepare before the class start to improve the accuracy and complexity, with enough thinking and correction. The second is the form. Generally, students pay less attention to the form in oral tasks than in the written forms. Therefore, the teacher may let students make a written form first to make the content of the report clear in mind, then to reorganize the general ideas when opening their mouth to speak out. The third is support. Teachers can provide students support when they complete the task. The support can be practical vocabulary, sentences, and pictures. So the students do not have to memory these items which may liberate their attention.

\subsubsection{Language Focus}

Language focus mainly concerns about teaching language points. This phase has two characteristics: 1) Language analysis activities. That means the teacher explain relative important or difficult language points which is needed in the process of completing the task. 2) Practice. After the task has been completed, students may look at the material again to have a better understanding: to look at difficult vocabulary and structures. Then students may wish to do some exercises which are followed by some communicative activities for them to practice the use of grammar.

\subsection{A Sample of TBLT Application}

The above is mainly concerned with the three stages of TBLT implementation. Actually, it is often the case that one task after another succeeds in the task-based classroom. And the latter ones are much more complicated than the former ones and form the task chain. According to Nunan, task chains mean that each exercise, activity and task should build upon the ones that have gone before (1989).

Sample design:

1. Topic: What are your parents' jobs?

2. Aims

(1) Cultivate speaking and thinking abilities and use English to communicate with each other through task completion.

(2) Ask and answer questions about one's job and use interview to strategies to find out information and take notes.

(3) Important structures:

What is your mother' /father's job? She is a doctor.

(4) Develop students' speaking skills.

3. Micro skills to be used

Brain-storming, note-taking, discussion, jigsaw

4. Modes of Task Completion

Individual work, Pair-work, Group work, Whole class work

5. Interaction mode

Teacher-students and students-students

6. Teaching Procedures:

(1) Pre-task

Each module starts with a "warming-up" exercise to introduce topic language and basic ideas for the theme.

The teacher shows students a picture and asks them where it is and who work in it. Students shout out the place and the name of the job. Then the teacher writes down the topic "What is your mother' /father's job?" on the blackboard, say:

My father is a worker and my mother is a manager. Can you think of some names of jobs?

Students come up with different kind of jobs: farmer, teacher, doctor, etc.

(2) Task cycle

Task A:

a. Group-work: 
The teacher divides the students into 8 groups and gives them some pictures. Ask the groups to recall the words related to the pictures.

b. Planning and report1

Planning: The teacher asks each group to plan a brief report for the whole class.

Report: Each group volunteer to represent their results.

Task B:

a. Jigsaws

Do an interview in each group, every student fill in the form independently, then the whole group share the results together. Last, each group chooses a representative to report their results.

b. Planning and report2

Planning: The students discuss in groups.

Report: The teacher asks the representatives from each group to make a report to the whole class.

\begin{tabular}{l|l|l|l}
\hline & Father's job & Mother's job & $\cdots \cdots$ \\
\hline S1 & & & \\
\hline S2 & & & \\
\hline S3 & & & \\
\hline
\end{tabular}

Task C:

a. Pair-work

Students work in pairs and find out their partners' ideal jobs. And ask their partner to explain why.

b. Planning and report3

Planning: The teacher asks each pair to plan a brief report for the whole class.

Report: Each student gives a report about his or her partner's ideal job.

(3) Post-speaking(language focus)

Task D:

Language Analysis Activity

Ask the students to read the dialogue on the book. And pay attention to the sentence structure.

Explain: what is your father's/mother's job?

What does your father/mother do?

What is your father/mother?

$\mathrm{He} / \mathrm{she}$ is a $\cdots$

Task E:

Oral English Practice

After the teaching of the sentence structure, ask students to make sentences by using the sentence structures mentioned above.

\subsection{Inspiration From the Application of TBLT to oral English Teaching in Junior High School}

\subsubsection{Choosing an Appropriate Topic}

It is very important for English teacher to choose an interesting and real life related topic which can arouse students' interest and provides them encouragement and motivation to participate in the activities. Then, the teacher may design some creative tasks according to the topic. While designing tasks, there are certain principles to follow: authenticity principle, form-function principle, task dependency principle and learning by doing. And the tasks should be of the appropriate level and difficulty, be focused on their aims between fluency, accuracy and complexity.

\subsubsection{Balancing Meanings and Forms}

In order to express oneself appropriately and effectively, one must master the language forms first. Language teaching aims at developing the students' ability to use the target language to communicate and interact with others. So both meanings and forms are important in English teaching and learning. Therefore, to keep the balance as much as possible, the teacher should pay attention to the following three aspects. First, when the teacher selects language items to teach or stress, he or she should balance the usage and use. That is to say, the teacher should ensure that the items have potential value for the students to communicate in real-life. Second, the language practice should be carried out in a meaningful setting, in response to the limitations of some English lessons. Third, during the feedback, the teacher should evaluate the students from both form and content.

\subsubsection{Developing the Teachers' Qualities}

TBLT can benefit the students a lot in English learning, but it requires teachers much more, including subject knowledge and a high level of teaching skill. On one hand, as English teachers, it is necessary for them to be solid in all aspects of the basic skills: listening, speaking, reading and writing. Only when the teachers themselves are very good at these skills, can they teach others how to do a better job. On the other hand, the teachers should also be more creative, flexible, devoted and enthusiastic in the class with TBLT. Because they will take the responsibility to organize the class, decide what to talk about, how to talk about the topic, how to organize the students and how to 
assess the students' work. They play different roles in the class, they may act as participants, controllers, assessors, prompters. So it is a challenge as well as an opportunity for the teachers, they should try their best to improve themselves.

In short, in the oral English teaching guided by the TBLT model, the interaction and communication among students help students use the language more effectively and correctly. The atmosphere is active, and the students' learning motivation and confidence have been greatly enhanced. The application of TBLT to oral English teaching will improve the Junior High School students's speaking competence, develop their cognitive ability, and cultivate their spirit of participation and cooperation in the process of completing tasks. Undoubtedly, TBLT is an effective way to improve Junior High School students' oral English.

\section{Conclusion}

With the further development of new curriculum reform, more and more teaching approaches will be introduced to English teaching. TBLT as an effective and practical method will be widely used. Meanwhile, oral English teaching has always been a weak part in Junior High School. TBLT provides a cheerful, creative and harmonious environment in which students are totally engaged in using English by means of negotiating, communicating and cooperating. Therefore, it is of great value to make a study on the application of TBLT to oral English teaching in Junior High School.

This paper has made the tentative study of the application of TBLT to oral English teaching in Junior High School. The study covers the previous study on task-based language teaching, the present situation of oral English teaching in Junior High School, the application of task-based language teaching in Oral English class.

The author hopes that the present study will help the teachers and students have a clear and better understanding of TBLT. And the author also hopes that the suggestions will help them use TBLT in Junior High School more effectively.

\section{References}

Gong, Y. and Luo, S. (2003). Task-based learning teaching. People's Education Press: Beijing.

Ministry of Education (2001). The interpretation of the national new standard for English curriculum. Beijing Normal University Press: Beijing.

Nunan, D. (1989). Designing tasks for the communicative classroom. Cambridge University Press: Cambridge,

Nunan, D. (1999). Second language teaching and learning. Cole Publishing Company. 24.

Widdowson, H. G. (1996). Language in Society. Oxford University Press.

Willis, J. (1996). A framework for task-based language learning. Longman Publish House: London.

Wu Xuesong Task-based oral English teaching. Nanjing Normal: Nanjing. 